\title{
Version 2.0 of the TXYZ Thermal
} Analysis Program: TXYZ20

$-Q C$ 100 .457 400-89 1992 C. 2 
$T$

he National Institute of Standards and Technology was established in 1988 by Congress to "assist industry in the development of technology ... needed to improve product quality, to modernize manufacturing processes, to ensure product reliability ... and to facilitate rapid commercialization ... of products based on new scientific discoveries."

NIST, originally founded as the National Bureau of Standards in 1901, works to strengthen U.S. industry's competitiveness; advance science and engineering; and improve public health, safety, and the environment. One of the agency's basic functions is to develop, maintain, and retain custody of the national standards of measurement, and provide the means and methods for comparing standards used in science, engineering, manufacturing, commerce, industry, and education with the standards adopted or recognized by the Federal Government.

As an agency of the U.S. Commerce Department's Technology Administration, NIST conducts basic and applied research in the physical sciences and engineering and performs related services. The Institute does generic and precompetitive work on new and advanced technologies. NIST's research facilities are located at Gaithersburg, MD 20899, and at Boulder, CO 80303. Major technical operating units and their principal activities are listed below. For more information contact the Public Inquiries Desk, 301-975-3058.

\section{Technology Services}

- Manufacturing Technology Centers Program

- Standards Services

- Technology Commercialization

- Measurement Services

- Technology Evaluation and Assessment

- Information Services

Electronics and Electrical Engineering Laboratory

- Microelectronics

- Law Enforcement Standards

- Electricity

- Semiconductor Electronics

- Electromagnetic Fields ${ }^{1}$

- Electromagnetic Technology ${ }^{1}$

Chemical Science and Technology Laboratory

- Biotechnology

- Chemical Engineering ${ }^{1}$

- Chemical Kinetics and Thermodynamics

- Inorganic Analytical Research

- Organic Analytical Research

- Process Measurements

- Surface and Microanalysis Science

- Thermophysics ${ }^{2}$

Physics Laboratory

- Electron and Optical Physics

- Atomic Physics

- Molecular Physics

- Radiometric Physics

- Quantum Metrology

- Ionizing Radiation

- Time and Frequency ${ }^{1}$

- Quantum Physics ${ }^{1}$
Manufacturing Engineering Laboratory

- Precision Engineering

- Automated Production Technology

- Robot Systems

- Factory Automation

- Fabrication Technology

Materials Science and Engineering Laboratory

- Intelligent Processing of Materials

- Ceramics

- Materials Reliability ${ }^{1}$

- Polymers

- Metallurgy

- Reactor Radiation

Building and Fire Research Laboratory

- Structures

- Building Materials

- Building Environment

- Fire Science and Engineering

- Fire Measurement and Research

Computer Systems Laboratory

- Information Systems Engineering

- Systems and Software Technology

- Computer Security

- Systems and Network Architecture

- Advanced Systems

Computing and Applied Mathematics Laboratory

- Applied and Computational Mathematics ${ }^{2}$

- Statistical Engineering ${ }^{2}$

- Scientific Computing Environments ${ }^{2}$

- Computer Services ${ }^{2}$

- Computer Systems and Communications ${ }^{2}$

- Information Systems

\footnotetext{
${ }^{1}$ At Boulder, CO 80303.
}

${ }^{2}$ Some elements at Boulder, CO 80303. 


\section{Version 2.0 of the TXYZ Thermal Analysis Program: TXYZ20}

John Albers

Semiconductor Electronics Division

Electronics and Electrical Engineering Laboratory

National Institute of Standards and Technology

Gaithersburg, MD 20899

June 1992

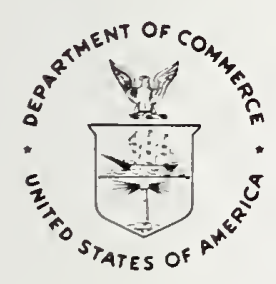

U.S. DEPARTMENT OF COMMERCE, Barbara Hackman Franklin, Secretary TECHNOLOGY ADMINISTRATION, Robert M. White, Under Secretary for Technology NATIONAL INSTITUTE OF STANDARDS AND TECHNOLOGY, John W. Lyons, Director 
National Institute of Standards and Technology Special Publication 400-89 Natl. Inst. Stand. Technol. Spec. Publ. 400-89, 33 pages (June 1992)

CODEN: NSPUE2

\section{U.S. GOVERNMENT PRINTING OFFICE} WASHINGTON: 1992

For sale by the Superintendent of Documents, U.S. Government Printing Office, Washington, DC 20402-9325 
Semiconductor Measurement Technology:

Version 2.0 of the TXYZ Thermal Analysis Program: TXYZ20

Table of Contents

Page

Abstract . . . . . . . . . . . . . ..... 1

Introduction . . . . . . . . . . . . . . . . . 2

Review of the Model, the TXYZ Code, and the TXYZ20 Code . . . . . . . . 2

Examples of Calculations with $\mathrm{TXYZ20}$. . . . . . . . . . . . . . 6

Benchmark Example . . . . . . . . . . . . . . . . . . 7

Other Examples . . . . . . . . . . . . . . . . . . . 10

Acknowledgments . . . . . . . . . . . . . . . . . . . . 18

References . . . . . . . . . . . . . . . . . . . 18

Appendix. TXYZ Version 2.0 . . . . . . . . . . . . . . . . . . . . . . . 19

List of Tables

Page

1. Annotated input data file (input1.dat) for TXYZ20 code . . . . . . . . . 8

2. Annotated output data file (output1.dat) for TXYZ20 program . . . . . . . 9

3. CPU times used in TXYZ20 calculation using input1.dat data . . . . . . . . . 11

4. Annotated input data file (input1a.dat) for TXYZ20 code . . . . . . . . . 11

5. Annotated input data file (input2.dat) for TXYZ20 code . . . . . . . . . . . 12

6. Annotated output data file (output2.dat) for TXYZ20 program . . . . . . . . 13

7. Annotated input data file (input3.dat) for TXYZ20 code . . . . . . . . . . . 14

8. Annotated output data file (output3.dat) for TXYZ20 program . . . . . . . 15 

Semiconductor Measurement Technology:

Version 2.0 of the TXYZ Thermal Analysis Program: TXYZ20

\author{
John Albers \\ Semiconductor Electronics Division \\ National Institute of Standards and Technology \\ Gaithersburg, Maryland 20899
}

\begin{abstract}
The TXYZ computer program has been used for a number of years for the thermal analysis of semiconductor devices and packages. This program makes use of the closed form, Fourier series solution of the steady-state heat flow equation for the general case of a rectangular three-layer structure with multiple heat sources on the top surface. TXYZ provides for the calculation of the temperature at any set of points in this structure and has proven useful for the determination of the steady-state temperature distribution of semiconductor chips and packages. This report presents TXYZ Version 2.0 (TXYZ20) which is a revised and updated version of the original TXYZ program. The TXYZ20 program incorporates more flexible handling of input data, assignment of positive or negative noninteger weights to the various heat sources or heat sinks, and improved evaluation of limiting forms in the code.
\end{abstract}

The first part of this report consists of a discussion of the general elements in the TXYZ code and the particular changes which have been made to it to obtain TXYZ20. The second part of the report contains a discussion of several examples of the running of the code. Several annotated input data files are presented and discussed to show both the increased flexibility of the input data and the actual use of the updated code. Running the TXYZ20 code for one of the input files provides a benchmark for several machines. The user may wish to run this example for the purpose of comparing the CPU times involved. The appendix contains an annotated, internally documented listing of the FORTRAN source code for TXYZ20.

The FORTRAN source code (total of about 21 kbytes) and sample input and output data files are available in ASCII format using a number of transfer vehicles. These include: standard 8-track magnetic tape (ASCII, density $=1600$, record $=80$, block $=1600), 5.25$ in. (360-kbyte and 1.2-Mbyte) DOS-formatted floppy disks, and electronic mail over the Internet. The sample input and output data files are included so that the user can check the program for proper operation as well as to become acquainted with the setup and use of the code. Users of the TXYZ code will find the updated TXYZ20 code easy to use and should benefit from the more flexible input and the more general treatment of heat sources and heat sinks.

Key words: FORTRAN; Fourier analysis; integrated circuit; semiconductor devices; semiconductor materials; steady-state heat flow; thermal analysis; thermal conductivity. 


\section{Introduction}

The operation of a semiconductor device relies on the passage of current through portions of the structure. This is accompanied by power dissipation and heating which gives rise to a temperature distribution. In time, thermal stresses may arise and lead to device degradation and possible failure. In addition to the effects of thermal stresses on device reliability, the modeling of the steady-state thermal response of a system is also useful since the temperature distribution may have an effect upon the local mechanical, thermal, electrical, or optical properties of the sysitem. Consequently, an accurate physical model of the temperature distribution under the power condition of actual operation is of great importance. It is also possible to ascertain the relative effects of composition (thermal conductivity) and geometry (layer thickness). By carefully optimizing composition and geometry, it may be possible to minimize the thermal stress and hence ensure optimal device lifetime.

The physical and mathematical model used here is taken from the work of Kokkas [1]. This has been used previously to construct the TXYZ program. The Kokkas model and the TXYZ code have been described in considerable detail in NBS Special Publication 400-76 [2]. This report is available and should be consulted for the details of the analysis which are still current and valid.

\section{Review of the Model, the TXYZ Code, and the TXYZ20 Code}

For the purposes of providing a background for the TXYZ20 code, a brief outline of the salient features of the earlier report on TXYZ is presented here. It is assumed that the reader has a copy of reference [2]. The symbols used here are defined in this reference. The outline presented here should provide the reader with an overview of the analysis and a quick guide as to where to find the various portions of the calculation.

The starting point of the calculation is the steady-state heat flow equation for a single rectangular layer. In Cartesian coordinates, this takes on the form

$$
\nabla^{2} T(x, y, z)=\left\{\frac{\partial^{2}}{\partial x^{2}}+\frac{\partial^{2}}{\partial y^{2}}+\frac{\partial^{2}}{\partial z^{2}}\right\} T(x, y, z)=0
$$

This equation is solved in this coordinate system using Fourier analysis. The requirement that there be no heat transport out of the lateral boundaries of the structure leaves only "quantized" cosine functions in the Fourier representation of the temperature,

$$
T(x, y, z)=\sum_{n=0}^{\infty} \sum_{m=0}^{\infty} \frac{4 \tau(n, m, z) \cos \left(n \pi x / L_{x}\right) \cos \left(m \pi y / L_{y}\right)}{\left(\delta_{n 0}+1\right)\left(\delta_{m 0}+1\right) L_{x} L_{y}}
$$

where $\delta_{n n^{\prime}}$ is the Kronecker delta and is equal to unity if $n=n^{\prime}$ and zero otherwise.

The Fourier coefficients, $\tau(n, m, z)$, are given by

$$
\tau(n, m, z)=\alpha \cosh (\gamma z)+\beta \sinh (\gamma z)
$$


where the coefficients $\alpha$ and $\beta$, which may be functions of $\gamma$, are determined from the two $z$-dependent boundary conditions.

The above analysis provides the basis for the general multiple-layer problem in terms of the Fourier coefficients. For this case, it is assumed that the temperature satisfies the steady-state equation in each of the layers. Consequently, in each of the layers, the Fourier expansion of the temperature takes the form

$$
\tau_{i}(n, m, z)=\alpha_{i} \cosh (\gamma z)+\beta_{i} \sinh (\gamma z),(i=1, \ldots, n) .
$$

For each layer, there are two coefficients which arise from the fact that the basic temperature equation is second order. These are determined from the $z$-dependent boundary conditions. The general set of $z$-dependent boundary conditions for the multiple layer problem is provided by the conditions that: heat enters (or leaves) the structure through the portions of the top layer where power is applied, the temperature and the heat flow are continuous across the internal interfaces, and the temperature is continuous across the interface between the bottom layer and the heat sink. The above equations and boundary conditions provide the mathematical framework in which the multiple layer problem may be solved. For the purposes of numerical modeling, the multiple layer problem is specialized to one with three layers. In this case, the Kokkas [1] analysis leads to the solution in the form

$$
T_{i}(x, y, z)=P_{0} \sum_{n=0}^{\infty} \sum_{m=0}^{\infty} \frac{4 U(n, m) \tau_{i}(n, m, z) \cos \left(n \pi x / L_{x}\right) \cos \left(m \pi y / L_{y}\right)}{\left(\delta_{n 0}+1\right)\left(\delta_{m 0}+1\right) L_{x} L_{y} \kappa_{1}} .
$$

The symbols, analysis and particular forms of $\tau_{i}(n, m, z)$ are discussed in some detail in reference [2]. There are several parts of the above equation which can be identified. First, there is the $z$-dependent part of the solution in each layer, $\tau_{i}(n, m, z)$. The two cosine functions, $\cos \left(n \pi x / L_{x}\right) \cos \left(m \pi y / L_{y}\right)$, arise from the $x$ - and $y$-dependent parts of the steady-state equation. Their specific form arises from the requirement of the lateral boundary conditions. Finally, the requirement that heat enters or leaves the top surface only through the heating elements introduces the function $P_{0} U(n, m)$. It should be noted that $P_{0}$ appears only in front of the sum. It is a scale or multiplicative factor which for convenience may be set equal to unity. Its effect is to scale the temperature in a direct linear fashion. Performing the calculation for $P_{0}=1$ for a given structure then provides the temperature distribution for arbitrary $P_{0}$ which can then be obtained by multiplying by the $P_{0}$ which is used.

In the above, the function, $U(n, m)$, is related to the heat sources (sinks) on the top surface of the structure. This function is defined as the double cosine transform of the geometric part of the surface power function, $U(x, y)$,

$$
U(n, m)=\int_{0}^{L_{x}} \int_{0}^{L_{y}} U(x, y) \cos \left(n \pi x / L_{x}\right) \cos \left(m \pi y / L_{y}\right) d x d y .
$$

The detailed form of this function is considered in reference [2]. There, the relation of this function to the location and size of the heat sources was presented. In addition, the 
limiting form of the function as either $n$ or $m$ approach zero was considered, and the correct limit was established for the purposes of numerical analysis. The reader is referred to that report for details.

In the original version of TXYZ, all heat sources had equal unit weights. If the user wanted to construct a more general heat source, this could only be done in unit increments by superimposing sources. Hence, to perform the calculation for a heating element which had five times the effect as another, the element would have to constructed five times. Only integer increments were possible. The first change made in TXYZ is the generalization of the heating elements. It should be noted that this does change the basic model. The updated TXYZ20 program allows for noninteger weights to be assigned to each heating element. This weight may be positive or negative and hence represent the effects of either a heat source or a heat sink. The weight is entered through the input data file and appears with the location and size of the element. The reader should refer to the last lines in the input data files presented in tables $1,4,5$, and 7 for the use of weighting of the heat elements. The more general information is then passed from the main program to the UZERO function through a COMMON statement. The weighting of the heating element was used originally in a calculation of the thermal interactions between electromigration test structures [3]. The careful and consistent evaluation of the temperature is important in this case as the test structures are used in accelerated testing and the temperature profile generated by one of the elements may increase the temperature at adjoining elements which may accelerate the failure rates. As electromigration is temperature dependent, it is of central importance to evaluate the temperature. This is especially the case where the thermal interaction of neighboring heating elements comes into play.

The weight is entered on the same line of the input data file where the position and lengths along $\mathrm{x}$ and $\mathrm{y}$ are entered. Instead of having to enter the same element five times, a weight of 5 may simply be used. In addition, noninteger weights which are positive or negative may be entered to represent sources or sinks. This feature should increase the versatility of the code to a more general class of problems.

Returning to the overview of the original TXYZ code and the basis for the evolution of TXYZ20, the behavior of the Fourier coefficients for both small and large values of the arguments is next on the agenda. The importance of this aspect of the analysis and the resulting numerical code is found in the fact that the equations involved contain the possibility of numerical infinities or overflow situations. These occur for $n=0$ and $m=0$ as well as for large values of these summation variables. The reason for the relatively compact nature of the original TXYZ code and its numerical efficiency is that great care was exercised in the investigation of the functions for the small and large argument regime. For small values of the argument, the evaluation of limiting forms led to expressions which were correct and free of artificial numerical singularities. For large values of the argument, special care was required. Many of the functions involved contained the hyperbolic sinh and cosh functions. These approach the exponential function for large values of the argument. These provide the possibility for numerical infinities or overflows. Careful investigation of the forms of the functions showed that these numerical infinities were removable by 
other numerical infinities. For example, an exponential in the numerator and denominator of a function would give rise to two overflows when evaluated by a computer but would cancel each other and give rise to a finite result when analytic evaluation was properly applied. The construction of the function, FUNZ, in the TXYZ code was based upon such evaluations and their numerical implementations. With the passage of time and the use of the TXYZ code, one place where such cancellation was found to be incomplete was in the case of a fairly thick middle layer. For most cases of interest to the modeling of the steady-state thermal response of semiconductor device structures, these layers are usually thin. However, this situation has now been carefully investigated and the numerically stable limiting form has been determined and used in the code in the middle layer portion of the FUNZ function. The introduction of the nonsingular limiting form is contained in the TXYZ20 code.

The original TXYZ report contains a section showing how the one-dimensional equations are obtained in the special case of a power source which completely covers the top surface. This analysis requires the careful evaluation of limits. When properly applied, the onedimensional expressions for the thermal resistance are obtained. The reader is referred to reference [2] for the details.

The last item to discuss before addressing the structure of the input data file for TXYZ20 is concerned with the effect of the upper summation limits on the calculated temperature. While this is discussed on pp. 32-33 and in figure 7 of reference [2], it is an important concept to understand and utilize correctly when running the code. Consider the case of a structure with lateral dimension of $L$ and a heat element of lateral dimension of $\Delta$. For the Fourier series to begin "seeing" this element, the cosine function in the basis set must have at least one complete cycle in $\Delta$. As the element is rectangular, one cycle is certainly not enough, as the cosine is a poor representation of the rectangle. Consequently, higher "frequencies" are in order to assure the adequacy of the representation. The rule of thumb is that the number of terms should be at least on the order of $L / \Delta$. A stronger rule of thumb would require several times the above rule of thumb. Certainly, the example of reference [2] for $L / \Delta=200$ shows that the asymptotic value of the temperature is attained for 400 to 500 terms. In general, the stronger rule of thumb should be applied to the smallest heat element in order to achieve better accuracy.

In its present form, TXYZ20 allows an upper limit of 500 terms. With smaller feature sizes, this upper limit may be inadequate. If this is the case, it is important to edit the FORTRAN source code for TXYZ20. This requires the following changes. First, the DIMENSION statements in the main program for $\operatorname{COSTY}(500), \operatorname{ARUZER}(500,500)$ and ARFUNZ $(500,500)$ must be increased. Second, the line which tests the input values of the two upper limits and stops execution of the program if they are too big must be turned off. The evolution of computers over the past decade has put more memory in the hands of the user. Increasing the size of the DIMENSION statements may just test the extent of this memory. Failure of the modified code to compile due to memory restrictions is the test.

A note of caution is in order here. If the test line is turned off and the upper limit is larger 
than the size of the DIMENSION statement, the calculation will proceed with values being stored in incorrect registers. No meaning should be ascribed to the results. Of course, the author is available for discussion and advice.

\section{Examples of Calculations with TXYZ20}

This portion of the report is concerned with examples of the input data file for the TXYZ20 code. The reader is encouraged to read through the listing of the FORTRAN source code for TXYZ20. In regard to the input data, special attention should be given to the internal documentation which is provided in the portion which describes the input section (see pp. 21-22). The variables and their use as well as the form of their input are all described in considerable detail there. Before describing the changes in the input data files, a special note is in order concerning the units used in the calculations. It is of utmost importance that the various input parameters be in a consistent set of units. Whatever length unit is used for the dimensions of the structure, the dimensions of the heat elements and the layer thicknesses must also be used in the thermal conductivities and the power density. Hence, if length is used for the former, then the thermal conductivities must be in the units of watts $/{ }^{\circ} \mathrm{C}$ length and the power density must be in the units of watts/(length) ${ }^{2}$.

The major changes in the input have to do with (1) the input or generation of the $x, y$, and $\mathrm{z}$ values to be used and (2) the input of the weighting factor for the heating elements. These are discussed in some detail here.

The input for the $x, y$, and $z$ values has been made more flexible and consistent. As the treatment of each of these is the same, discussion will be focused on only the first.

The first five lines of the input data file remains the same as that used in the original TXYZ code. These contain the dimensions of the rectangular structure, the thickness, and thermal conductivity of the three layers and the summation limits for the double sum. The sixth line contains the integer index, IEDGEX. This is used for the generation or input of the values of $x$ to be used in the calculation. If IEDGEX $=1$, then a set of equispaced values of $\mathrm{x}$ will be generated. For this case, the next line of the input data file is to contain three numbers. These are: ILX (the number of $\mathrm{x}$ values to be generated), X1 (the value of the first $x$ point), and STEPX (the value of the increment in $x$ ). Once these numbers are read in, the program constructs the set of points according to

$$
\mathrm{X}(\mathrm{I})=\mathrm{X} 1+(\mathrm{I}-1)^{*} \operatorname{STEPX}(\mathrm{I}=1, \ldots, \mathrm{ILX}) .
$$

If $\operatorname{IEDGEX}=2$, then a set of values of $\mathrm{x}$ will be read from the data file. For this case, the the next line of the input data file will contain the number of $\mathrm{x}$ values to be read, ILX. The program will then read in ILX lines of input data file containing one value of $\mathrm{x}$ for each line. The IEDGEX $=2$ option allows for the calculation to be performed at a set of $\mathbf{x}$ values which are not necessarily equispaced. This is particularly useful if the user wants to have some of the $\mathrm{x}$ values closely spaced on or near a heat element and other values spread out away from the heat element. This option is motivated by the fact that the temperature is usually rapidly varying near the element and slowly varying away from it. 
Once the values of $x$ have been generated or read, the code goes on to generate or read the values of $y$ and then to generate or read the values of $z$ by the same construction. As noted in the source code internal documentation (see pp. 21-22), the information on the generation or reading of the $\mathrm{z}$ values is always entered as positive quantities. The code takes care of making the appropriate sign changes.

The other major change in the input data file is the introduction of the weighting factor for each heat element. Once the number of heat elements has been read in along with the power density, the information for each of the heating elements is then read. For each element, a single line of five numbers contains all of the information. The weighting factor is the first entry on the line. Hence, the line contains WTSOUR(I), XSOUR(I), YSOUR(I), LXSOUR(I), AND LYSOUR(I). WTSOUR(I) is the weighting factor (positive for source, negative for sink) for the $\mathrm{i}$-th element. This is a REAL number and does not have to be INTEGER.

The above features make the structure of the input data file more flexible and consistent. It is important to note, as has been discussed before, that the power density variable, $P_{0}$, be set equal to unity. In effect, the calculation then generates a scaled temperature, $T(x, y, x) / P_{0}$, which may always be rescaled for a particular value of $P_{0}$.

Before turning to the examples, it is also important to note the changes made in the output data file. The format used for the construction of the output data is of a general nature. It has been written to accommodate a wide range of numerical values without loss of generality or data. This was motivated by the fact that datum may be lost on output if it exceeds the format of the write statement. In order to circumvent this, the data may appear to have more significant figures than might be reasonable or needed. The user should keep this in mind when looking at the output. The user should round the output following accepted rules for this process. All the WRITE statements in the FORTRAN source code direct output to logical device for012. The one exception is the line which is written if either one or both of the upper summation limits exceeds the dimensionality of the arrays used. This terminates program execution. Assuming that this is not the case, the data which are written to for012 are $\mathrm{x}, \mathrm{y}, \mathrm{z}, \mathrm{T}(\mathrm{x}, \mathrm{y}, \mathrm{z})$. The major loop in the code $(3000)$ is involved with the various $z$ values used. Once the list of $x, y$, and $z$ values for the calculations of $T(x, y, z)$ has been completed, the remaining section of the output data file contains the listing of the input variables used in the calculations. Saving the output data without some identifier of the input data can present problems as to where the output came from. This is taken care of with the present listing to for 012 .

\section{Benchmark Example}

The first example is contained in the two files, input1.dat and output1.dat. This is for the case of a single heat source of unit weight. The temperature is calculated for 11 values of $x$. The example is illustrative of the use of the TXYZ20 code. The reader is referred to the annotated input and output data files (see tables 1 and 2) where each line of the file is described. This particular problem is of interest as it requires a small amount of time to carry out but does provide for some indication of the relative speeds which users can 
Table 1. Annotated input data file (input1.dat) for TXYZ20 code.

The data correspond to those contained in the file input1.dat which can be used to run the case of a single heat source of unit weight. This illustrates the use of the IEDGEX = 1 generation of a set of values of $x$ to be used in the calculation. In this and subsequent annotated input data file listings, it is important for the user to keep in mind the comments of p. 6 regarding the consistency of the units to be used in the calculation.

\section{INPUT DATA}

100100

1.001

5.0001

4.005

500500

1

110.010 .

1

150.0 .0

1

$\begin{array}{lll}1 & 0.0 & 0.0\end{array}$

11.0

$1 \quad 40.0 \quad 20.0 \quad 40.0 \quad 20.0$
DESCRIPTION OF INPUT DATA

$X$ AND $Y$ DIMENSIONS OF RECTANGULAR STRUCTURE THICKNESS AND THERMAL CONDUCTIVITY OF TOP LAYER THICKNESS AND THERMAL CONDUCTIVITY OF MIDDLE LAYER THICKNESS AND THERMAL CONDUCTIVITY OF BOTTOM LAYER UPPER SUMMATION LIMITS FOR $N$ AND M SUMMATIONS IEDGEX $(=1$, THEN READ IN THREE VALUES ON NEXT LINE) NUMBER OF VALUES, FIRST POINT, INCREMENT

IEDGEY ( $=1$, THEN READ IN THREE VALUES ON NEXT LINE) NUMBER OF VALUES, FIRST POINT, INCREMENT

IEDGEZ $(=1$, THEN READ IN THREE VALUES ON NEXT LINE) NUMBER OF VALUES, FIRST POINT, INCREMENT

NUMBER OF SOURCES AND POWER DENSITY

WEIGHT, $X$, LENGTH ALONG $X, Y$, LENGTH ALONG $Y$ 
Table 2. Annotated output data file (output1.dat) for TXYZ20 program.

The data correspond to those contained in the file output1.dat which is generated for the case of a single heat source of unit weight.

The first block of $l i$ nes are the $x, y, z$, and calculated $t(x, y, z)$ values. Beyond these are the listing of the input variables. In this and subsequent annotated output data file listings, it is important for the user to keep in mind the comments of $p .7$ regarding the format used for the output data and the possible need for rounding.

\begin{tabular}{|c|c|c|c|}
\hline$x$ & $y$ & $z$ & $t(x, y, z)$ \\
\hline $0.0000000 E+00$ & 50.00000 & $0.0000000 E+00$ & 107.2166 \\
\hline 10.00000 & 50.00000 & $0.0000000 E+00$ & 229.7415 \\
\hline 20.00000 & 50.00000 & $0.0000000 E+00$ & 899.0788 \\
\hline 30.00000 & 50.00000 & $0.0000000 E+00$ & 3868.299 \\
\hline 40.00000 & 50.00000 & $0.0000000 E+00$ & 17908.64 \\
\hline 50.00000 & 50.00000 & $0.0000000 E+00$ & 29526.74 \\
\hline 60.00000 & 50.00000 & $0.0000000 E+00$ & 17908.62 \\
\hline 70.00000 & 50.00000 & $0.0000000 E+00$ & 3868.297 \\
\hline 80.00000 & 50.00000 & $0.0000000 E+00$ & 899.0831 \\
\hline 90.00000 & 50.00000 & $0.0000000 E+00$ & 229.7416 \\
\hline 100.0000 & 50.00000 & $0.0000000 E+00$ & 107.2136 \\
\hline
\end{tabular}

THERMAL CONDUCTIVITIES AND LAYER THICKNESSES

$L X=100.00 \quad L Y=100.00$

$L 1=\quad 1.00000 \mathrm{~L} 2=\quad 5.00000 \mathrm{~L} 3=\quad 4.00000$

$\mathrm{K} 1=0.00100000 \mathrm{~K} 2=0.00010000 \mathrm{~K} 3=0.00500000$

UPPER SUMMATION LIMITS NUP $=500 \quad$ MUP $=500$

NUMBER OF HEAT SOURCES $=1$

POWER DENSITY $=1.000000$

COORDINATES, LENGTHS, AND WIDTHS OF HEAT SOURCES

$\begin{array}{llll}\text { HEAT SOURCE WTSOUR XSOUR YXSOUR LYSOUR } & \text { LSOUR }\end{array}$

$\begin{array}{llllll}1 & 1.00000 & 40.00000 & 40.00000 & 20.00000 & 20.00000\end{array}$


expect to see in the execution of the code. This particular input data file was used for the TXYZ20 code on several machines [4]. These include: a VAX 11/785, a SUN, a SPARC 2 and a CRAY. All of these systems had sufficient memory to compile the code and run it for the upper limits of 500. Users of the code on PCs may have to experiment to see if the dimension statements and the upper limits are too large. This will be influenced by the amount of RAM as well as the presence of a coprocessor. The execution of the code for this problem shows a range of relative speeds from 1 to 55 . The results of this benchmark example are presented in table 3.

The above example makes use of the IEDGE $=1$ option for data entry. This can also be accomplished by using the IEDGE $=2$ option. This alternative is contained in the file input1a.dat which is annotated in table 4. The output from running these data is the same as contained in output1. dat (illustrated in table 2).

\section{Other Examples}

Several other examples are provided in the corresponding input and output data files. These show the use of the code for cases of (1) nonuniformly spaced points, and (2) several heat elements with various weights.

These are contained in the input2.dat and input3.dat files with the corresponding output data files of output2.dat and output3.dat. The example of input2.dat and output2.dat is annotated in tables 5 and 6.

This is for the case of a thick middle layer in the structure which can be handled with TXYZ20. The example of input3.dat and output3.dat is illustrated in tables 7 and 8 . The specific example shows how to construct the problem for the case of two elements where one is a heat source and the other is a heat sink. Nonequispaced sets of $\mathrm{x}$ and $\mathrm{z}$ values are also used in the calculation. These examples contain all of the features of the use of the TXYZ20 code.

All of the input and output data files are provided to give the user hands-on experience with the use of the code and to make sure that the code is properly working on the user's machine.

Values of the thermal conductivity of materials of interest to the semiconductor community may be found in reference [5]. The use of the basic TXYZ code for thermal characterization is discussed there.

The code has also been used in the original TXYZ form for the modeling of MMIC devices (GaAs) for the determination of the channel temperature when the devices are undergoing life testing [6].

Finally, the field of thermal resistance measurements has been reviewed [7]. This reference contains results which are related to the use of the original TXYZ code. 
Table 3. CPU times used in TXYZ20 calculation using input1.dat data.

This table presents the CPU time needed to carry out the calculation using the data in input1.dat (annotated in table 1) on several machines. This information is intended to provide a benchmark for the running of the TXZY2O code. The machines represented were used due to availability and do not represent a recommendation. The relative speeds presented cover a good deal of the spectrum to be expected.

\begin{tabular}{lcc} 
Machine & CPU & Relative speed \\
\hdashline VAX & -- & 1 \\
SUN & $457 \mathrm{sec}$. & 2.2 \\
SPARC 2 & $205 \mathrm{sec}$. & 7.6 \\
CRAY & $60 \mathrm{sec}$. & 55
\end{tabular}

Table 4. Annotated input data file (input1a.dat) for TXYZ20 code.

The data correspond to those contained in the file inputla.dat which can be used to run the case of a single heat source of unit weight. This illustrates the use of the IEDGEX = 2 generation of a set of values of $x$ to be used in the calculation. The final set of data is equivalent to that of input1.dat for IEDGE $=1$. The output is the same as that contained in output1.dat (discussed in table 2).

INPUT DATA

100100

1.001

5.0001

4.005

500500

2

11

0.0

10.

20.

30 .

40.

50.

60.

70.

80.

90.

100.

1

150.0 .0

1

$\begin{array}{lll}1 & 0.0 & 0.0\end{array}$

11.0

$140.0 \quad 20.0 \quad 40.0 \quad 20.0$

\section{DESCRIPTION OF INPUT DATA}

$X$ AND $Y$ DIMENSIONS OF RECTANGULAR STRUCTURE THICKNESS AND THERMAL CONDUCTIVITY OF TOP LAYER THICKNESS AND THERMAL CONDUCTIVITY OF MIDDLE LAYER THICKNESS AND THERMAL CONDUCTIVITY OF BOTTOM LAYER UPPER SUMMATION LIMITS FOR $N$ AND $M$ SUMMATIONS IEDGEX $(=2$, THEN READ IN INDIVIDUAL VALUES) NUMBER OF VALUES

$X(1)$ FIRST VALUE OF $X$

$X(2)$ SECOND VALUE OF $X$

$X(3)$

$X(4)$

$X(5)$

$\mathrm{X}(6)$

$\mathrm{X}(7)$

$X(8)$

$X(9)$

$X(10)$

$X(11)$ ELEVENTH VALUE OF $X$

IEDGEY ( $=1$, THEN READ IN THREE VALUES ON NEXT LINE) NUMBER OF VALUES, FIRST POINT, INCREMENT IEDGEZ ( $=1$, THEN READ IN THREE VALUES ON NEXT LINE) NUMBER OF VALUES, FIRST POINT, INCREMENT NUMBER OF SOURCES AND POWER DENSITY WEIGHT, $X$, LENGTH ALONG $X, Y$, LENGTH ALONG $Y$ 
Table 5. Annotated input data file (input2.dat) for TXYZ20 code.

The data correspond to those contained in the file input2.dat which is used to illustrate the use of the IEDGEZ $=2$ generation of a set of values of $z$ to be used in the calculation. This is for the case of a thick middle layer where the original TXYZ code had difficulty with an artificial overflow. The output for this case is contained in output2.dat and is discussed in table 6 .

INPUT DATA

$\begin{array}{lll}1060.00 \quad 280.00 \\ 3.0 & .00011 \\ 250 & .00011 \\ 0.1 & .00011 \\ 50 & 50 \\ 1 & \\ 1 & 0 . & 0 . \\ 1 & 0 . \\ 1 & 0 . & 0 . \\ 2 & \end{array}$

10

0 .

1.0

2.0

3.0

4.0

4.5

100 .

200.

230 .

240.

11.0

10.53 .0 .14 .
DESCRIPTION OF INPUT DATA

$X$ AND $Y$ DIMENSIONS OF RECTANGULAR STRUCTURE THICKNESS AND THERMAL CONDUCTIVITY OF TOP LAYER THICKNESS AND THERMAL CONDUCTIVITY OF MIDDLE LAYER THICKNESS AND THERMAL CONDUCTIVITY OF BOTTOM LAYER UPPER SUMMATION LIMITS FOR N AND M SUMMATIONS IEDGEX $(=1$, THEN READ IN THREE VALUES ON NEXT LINE) NUMBER OF VALUES, FIRST POINT, INCREMENT IEDGEY ( $=1$, THEN READ IN THREE VALUES ON NEXT LINE) NUMBER OF VALUES, FIRST POINT, INCREMENT IEDGEZ $(=2$, THEN READ IN INDIVIDUAL VALUES) NUMBER OF VALUES

$Z$ (1) FIRST VALUE OF $Z$

$Z$ (2) SECOND VALUE OF $Z$

$Z(3)$

Z(4)

Z(5)

Z(6)

$Z(7)$

Z(8)

Z(9)

$Z$ (10) TENTH VALUE OF $Z$

NUMBER OF SOURCES AND POWER DENSITY

WEIGHT, $X$, LENGTH ALONG $X, Y$, LENGTH ALONG $Y$ 
Table 6. Annotated output data file (output2.dat) for TXYZ20 program.

The data correspond to those contained in the file output2. dat which is generated from the input data contained in input2. dat (see table 5).

The first block of $l$ ines are the $x, y, z$, and calculated $t(x, y, z)$ values. Beyond these are the listing of the input variables.
$0.0000000 E+00$
$\stackrel{y}{0.0000000 E+00}$
$0.0000000 E+00$
$t(x, y, z)$
$0.0000000 E+00$
$0.0000000 E+00$
$-1.000000$
233445.2
$0.0000000 E+00$
$0.0000000 E+00$
$-2.000000$
224832.5
$0.0000000 E+00$
$0.0000000 E+00$
$-3.000000$
216600.1
$0.0000000 E+00$
$0.0000000 E+00$
$-4.000000$
208748.5
$0.0000000 E+00$
$0.0000000 E+00$
$-4.500000$
201273.0
$0.0000000 E+00$
$0.0000000 E+00$
$-100.0000$
197674.8
$0.0000000 E+00$
$0.0000000 E+00$
$-200.0000$
29815.45
$0.0000000 E+00$
$0.0000000 E+00$
$-230.0000$
7110.651
2989.828
$0.0000000 E+00$
$0.0000000 E+00-240.0000$
1686.604

STEADY-STATE THERMAL ANALYSIS CALCULATION USING EQS. (13)-(23) OF KOKKAS

THERMAL CONDUCTIVITIES AND LAYER THICKNESSES

$L X=1060.00 \quad L Y=280.00$

$\mathrm{L} 1=3.00000 \mathrm{~L} 2=250.00000 \mathrm{~L} 3=0.10000$

$K 1=0.00011000 K 2=0.00011000 \quad K 3=0.00011000$

UPPER SUMMATION LIMITS NUP $=50$ MUP $=50$

NUMBER OF HEAT SOURCES $=1$

POWER DENSITY $=1.000000$

COORDINATES, LENGTHS, AND WIDTHS OF HEAT SOURCES

HEAT SOURCE WTSOUR XSOUR YSOUR LXSOUR LYSOUR

$\begin{array}{llllll}1 & 1.00000 & 0.00000 & 0.00000 & 53.00000 & 14.00000\end{array}$


Table 7. Annotated input data file (input3.dat) for TXYZ20 code.

The data correspond to those contained in the file input3.dat which is used to illustrate the use of the IEDGEX $=2$ and IEDGEZ $=2$ generation of a set of values of $x$ and $z$ to be used in the calculation. In addition, two elements are used. One is a source with a weight of 1.0 and the other is a sink with a weight of -1.0 . The output for this case is contained in output2. dat and is discussed in table 8.

\section{INPUT DATA}

100100

1.001

5.0001

4.005

500500

2

10

40.

45.

46.

47.

48.

52.

53.

54.

55 .

60.

1

150.0 .0

2

9

0.0

1.0

2.0

3.0

4.0

5.0

6.0

9.0

10.0

21.0

1. $\quad 35.0 \quad 10.0 \quad 45.0 \quad 10.0$

$\begin{array}{lllll}-1 . & 55.0 & 10.0 & 45.0 & 10.0\end{array}$

\section{DESCRIPTION OF INPUT DATA}

$X$ AND $Y$ DIMENSIONS OF RECTANGULAR STRUCTURE THICKNESS AND THERMAL CONDUCTIVITY OF TDP LAYER THICKNESS AND THERMAL CONDUCTIVITY OF MIDDLE LAYER THICKNESS AND THERMAL CONDUCTIVITY OF BOTTOM LAYER UPPER SUMMATION LIMITS FOR $N$ AND M SUMMATIONS IEDGEX ( $=2$, THEN READ IN INDIVIDUAL VALUES) NUMBER OF VALUES

$X(1)$ FIRST VALUE OF $X$

$X(2)$ SECOND VALUE OF $X$

$x(3)$

$x(4)$

$x(5)$

$x(6)$

$x(7)$

$x(8)$

$x(9)$

$X(10)$ TENTH VALUE OF $X$

IEDGEY ( $=1$, THEN READ IN THREE VALUES ON NEXT LINE) NUMBER OF VALUES, FIRST POINT, INCREMENT

IEDGEZ $(=2$, THEN READ IN INDIVIDUAL VALUES) NUMBER OF VALUES

$Z$ (1) FIRST VALUE OF $Z$

$Z$ (2) SECOND VALUE OF $Z$

$Z(3)$

$Z(4)$

$Z(5)$

$Z(6)$

$Z(7)$

$Z(8)$

Z(9) NINTH VALUE OF $Z$

NUMBER OF SOURCES AND POWER DENSITY

WEIGHT, $X$, LENGTH ALONG $X, Y$, LENGTH ALONG $Y$ WEIGHT, $X$, LENGTH ALONG $X, Y$, LENGTH ALONG $Y$ 
Table 8. Annotated output data file (output3.dat) for TXYZ20 program.

The data correspond to those contained in the file output3.dat which is generated from the input data contained in input3.dat (see table 7).

The first block of $l$ ines are the $x, y, z$, and calculated $t(x, y, z)$ values. Beyond these are the listing of the input variables. This example has been constructed to show not only variable $x$ and $z$ but also the use of negative weights on the elements in the construction of heat sinks. In this particular case, the two elements are of equal size are are symmetrically placed with respect to the middle of the structure. The calculated $t(x, y, z)$ values directly reflect the opposite but equal weights of the two elements.

$\begin{array}{cccr}x & y & z & t(x, y, z) \\ 40.00000 & 50.00000 & 0.0000000 E+00 & 13895.94 \\ 45.00000 & 50.00000 & 0.0000000 E+00 & 8401.479 \\ 46.00000 & 50.00000 & 0.0000000 E+00 & 6187.981 \\ 47.00000 & 50.00000 & 0.0000000 E+00 & 4418.474 \\ 48.00000 & 50.00000 & 0.0000000 E+00 & 2844.606 \\ 52.00000 & 50.00000 & 0.0000000 E+00 & -2844.609 \\ 53.00000 & 50.00000 & 0.0000000 E+00 & -4418.476 \\ 54.00000 & 50.00000 & 0.0000000 E+00 & -6187.989 \\ 55.00000 & 50.00000 & 0.0000000 E+00 & -8401.491 \\ 60.00000 & 50.00000 & 0.0000000 E+00 & -13895.94 \\ 40.00000 & 50.00000 & -1.000000 & 13214.03 \\ 45.00000 & 50.00000 & -1.000000 & 8048.078 \\ 46.00000 & 50.00000 & -1.000000 & 6112.896 \\ 47.00000 & 50.00000 & -1.000000 & 4373.840 \\ 48.00000 & 50.00000 & -1.000000 & 2817.945 \\ 52.00000 & 50.00000 & -1.000000 & -2817.947 \\ 53.00000 & 50.00000 & -1.000000 & -4373.844 \\ 54.00000 & 50.00000 & -1.000000 & -6112.901 \\ 55.00000 & 50.00000 & -1.000000 & -8048.083 \\ 60.00000 & 50.00000 & -1.000000 & -13214.03 \\ 40.00000 & 50.00000 & -2.000000 & 9877.484 \\ 45.00000 & 50.00000 & -2.000000 & 6111.877 \\ 46.00000 & 50.00000 & -2.000000 & 4777.800 \\ 47.00000 & 50.00000 & -2.000000 & 3481.801 \\ 48.00000 & 50.00000 & -2.000000 & 2265.086 \\ 52.00000 & 50.00000 & -2.000000 & -2265.088 \\ 53.00000 & 50.00000 & -2.000000 & -3481.803 \\ 54.00000 & 50.00000 & -2.000000 & -4777.805 \\ 55.00000 & 50.00000 & -2.000000 & -6111.882 \\ 60.00000 & 50.00000 & -2.000000 & -9877.482 \\ 40.00000 & 50.00000 & -3.000000 & 7033.427 \\ 45.00000 & 50.00000 & -3.000000 & 4407.094 \\ 46.00000 & 50.00000 & -3.000000 & 3498.253 \\ 47.00000 & 50.00000 & -3.000000 & 2583.641 \\ 48.00000 & 50.00000 & -3.000000 & 1695.754 \\ 52.00000 & 50.00000 & -3.000000 & -1695.755 \\ 53.00000 & 50.00000 & -3.000000 & -2583.643 \\ 54.00000 & 50.00000 & -3.000000 & -3498.257 \\ 55.00000 & 50.00000 & -3.000000 & -4407.097 \\ 60.00000 & 50.00000 & -3.000000 & -7033.424\end{array}$




\begin{tabular}{|c|c|c|c|}
\hline$x$ & $y$ & z & $t(x, y, z)$ \\
\hline 40.00000 & 50.00000 & -4.000000 & 4544.860 \\
\hline 45.00000 & 50.00000 & -4.000000 & 2873.673 \\
\hline 46.00000 & 50.00000 & -4.000000 & 2300.854 \\
\hline 47.00000 & 50.00000 & -4.000000 & 1713.657 \\
\hline 48.00000 & 50.00000 & -4.000000 & 1131.903 \\
\hline 52.00000 & 50.00000 & -4.000000 & -1131.905 \\
\hline 53.00000 & 50.00000 & -4.000000 & -1713.658 \\
\hline 54.00000 & 50.00000 & -4.000000 & -2300.855 \\
\hline 55.00000 & 50.00000 & -4.000000 & -2873.675 \\
\hline 60.00000 & 50.00000 & -4.000000 & -4544.859 \\
\hline 40.00000 & 50.00000 & -5.000000 & 2285.325 \\
\hline 45.00000 & 50.00000 & -5.000000 & 1453.400 \\
\hline 46.00000 & 50.00000 & -5.000000 & 1169.267 \\
\hline 47.00000 & 50.00000 & -5.000000 & 875.0942 \\
\hline 48.00000 & 50.00000 & -5.000000 & 580.2814 \\
\hline 52.00000 & 50.00000 & -5.000000 & -580.2822 \\
\hline 53.00000 & 50.00000 & -5.000000 & -875.0949 \\
\hline 54.00000 & 50.00000 & -5.000000 & -1169.268 \\
\hline 55.00000 & 50.00000 & -5.000000 & -1453.401 \\
\hline 60.00000 & 50.00000 & -5.000000 & -2285.325 \\
\hline 40.00000 & 50.00000 & -6.000000 & 139.8420 \\
\hline 45.00000 & 50.00000 & -6.000000 & 90.59629 \\
\hline 46.00000 & 50.00000 & -6.000000 & 73.84338 \\
\hline 47.00000 & 50.00000 & -6.000000 & 56.01737 \\
\hline 48.00000 & 50.00000 & -6.000000 & 37.57924 \\
\hline 52.00000 & 50.00000 & -6.000000 & -37.57928 \\
\hline 53.00000 & 50.00000 & -6.000000 & -56.01740 \\
\hline 54.00000 & 50.00000 & -6.000000 & -73.84344 \\
\hline 55.00000 & 50.00000 & -6.000000 & -90.59635 \\
\hline 60.00000 & 50.00000 & -6.000000 & -139.8419 \\
\hline 40.00000 & 50.00000 & -9.000000 & 31.62482 \\
\hline 45.00000 & 50.00000 & -9.000000 & 20.66124 \\
\hline 46.00000 & 50.00000 & -9.000000 & 16.93877 \\
\hline 47.00000 & 50.00000 & -9.000000 & 12.92600 \\
\hline 48.00000 & 50.00000 & -9.000000 & 8.715524 \\
\hline 52.00000 & 50.00000 & -9.000000 & -8.715535 \\
\hline 53.00000 & 50.00000 & -9.000000 & -12.92601 \\
\hline 54.00000 & 50.00000 & -9.000000 & -16.93879 \\
\hline 55.00000 & 50.00000 & -9.000000 & -20.66125 \\
\hline 60.00000 & 50.00000 & -9.000000 & -31.62481 \\
\hline 40.00000 & 50.00000 & -10.00000 & $0.0000000 E+00$ \\
\hline 45.00000 & 50.00000 & -10.00000 & $0.0000000 E+00$ \\
\hline 46.00000 & 50.00000 & -10.00000 & $0.0000000 E+00$ \\
\hline 47.00000 & 50.00000 & -10.00000 & $0.0000000 E+00$ \\
\hline 48.00000 & 50.00000 & -10.00000 & $0.0000000 E+00$ \\
\hline 52.00000 & 50.00000 & -10.00000 & $0.0000000 E+00$ \\
\hline 53.00000 & 50.00000 & -10.00000 & $0.0000000 E+00$ \\
\hline 54.00000 & 50.00000 & -10.00000 & $0.0000000 E+00$ \\
\hline 55.00000 & 50.00000 & -10.00000 & $0.0000000 E+00$ \\
\hline 60.00000 & 50.00000 & -10.00000 & $0.0000000 E+00$ \\
\hline
\end{tabular}


STEADY-STATE THERMAL ANALYSIS CALCULATION USING EQS. (13)-(23) OF KOKKAS

THERMAL CONDUCTIVITIES AND LAYER THICKNESSES

$L X=100.00 \quad L Y=100.00$

$L 1=\quad 1.00000 \mathrm{~L} 2=5.00000 \mathrm{~L} 3=4.00000$

$K 1=0.00100000 K 2=0.00010000 K 3=0.00500000$

UPPER SUMMATION LIMITS NUP $=500$ MUP $=500$

NUMBER OF HEAT SOURCES $=2$

POWER DENSITY $=1.000000$

COORDINATES, LENGTHS, AND WIDTHS OF HEAT SOURCES

$\begin{array}{lllll}\text { HEAT SOURCE HTSOUR XSOUR YXSOUR } & \text { YYSOUR }\end{array}$

$\begin{array}{llllll}1 & 1.00000 & 35.00000 & 45.00000 & 10.00000 & 10.00000\end{array}$

$\begin{array}{llllll}1 & -1.00000 & 55.00000 & 45.00000 & 10.00000 & 10.00000\end{array}$ 


\section{Acknowledgments}

The author would like to thank Harry Schafft for his continued use of the code and the collaboration on the electromigration problem which fostered the variable weight idea and the use of the code for sinks as well as sources.

The author would also like to thank Dave Blackburn for using the code for two-dimensional temperature contour generation and for using thick middle layers which gave interesting results.

Finally, the author thanks all of the TXYZ users for making use of the code. He hopes that TXYZ users become TXYZ20 users.

\section{References}

[1] Kokkas, A. G., Thermal Analysis of Multiple-Layer Structures, IEEE Trans. Electron Devices ED-21, 674-681 (1974).

[2] Albers, J., Semiconductor Measurement Technology: TXYZ: A Program for Semiconductor IC Thermal Analysis, NBS Special Publication 400-79 (April 1984).

[3] Schafft, H. A., and Albers, J., Thermal Interactions Between Electromigration Test Structures, IEEE Proceedings on Microelectronic Test Structures, Vol. 1, No. 1, pp. 132-137 (February 1988).

[4] Certain commercial equipment, instruments, or materials are identified in this paper in order to specify the procedure adequately. Such identification does not imply recommendation or endorsement by the National Institute of Standards and Technology, nor does it imply that the materials or equipment identified are necessarily the best available for the purpose. In spite of the author's experience that the program performs correctly with every set of data which has been tried, there can be no assurance that the program will perform equally well on all (possibly anomalous) data. Therefore, both the author and NIST assume no liability for any possible losses resulting from the use of this program.

[5] Oettinger, F. F., Thermal Evaluation of VLSI Packages Using Test Chips - A Critical Review, Solid State Technology (February 1984).

[6] Wright, J. L., Marks, B. W., and Decker, K. D., Modeling of MMIC Devices for Determining MMIC Channel Temperatures During Life Tests, Proceedings of the Seventh IEEE SEMI-THERM Symposium, pp. 131-139 (1991).

[7] Oettinger, F. F., and Blackburn, D. L., Semiconductor Measurement Technology: Thermal Resistance Measurements, NIST Special Publication 400-86 (July 1990). 


\section{APPENDIX}

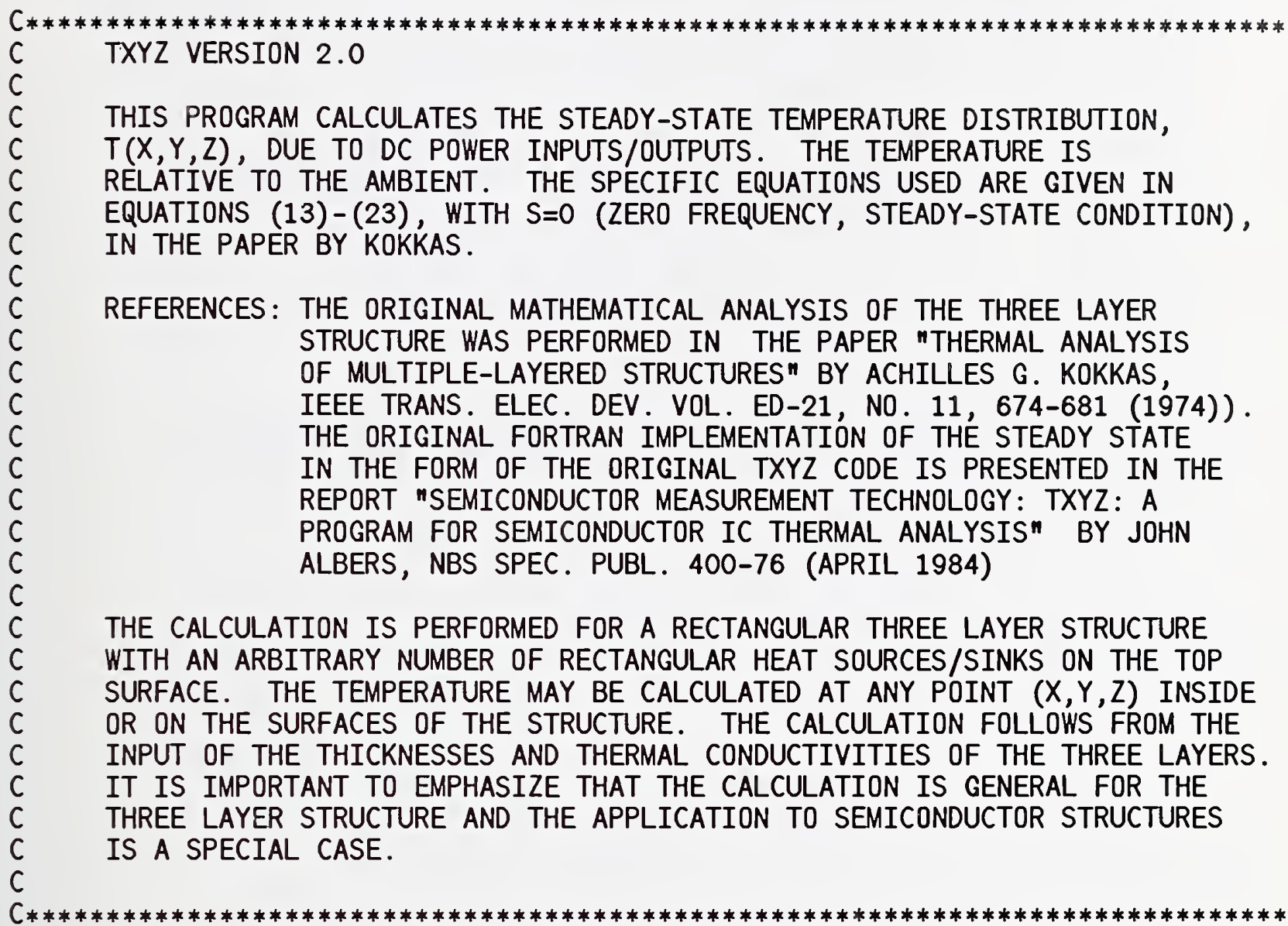


DIMENSION $X(100), Y(100), Z(100), \operatorname{COSYT}(500)$

DIMENSION ARUZER $(500,500)$, ARFUNZ $(500,500)$

DIMENSION WTSOUR (50), XSOUR(50), YSOUR (50),

REAL LXSOUR(50), LYSOUR(50), K1, K2, K3, LX, LY, L1, L2, L3

COMMON K1, K2, K3, LX, LY, L1, L2, L3

COMMON NSOUR, WTSOUR, XSOUR, YSOUR, LXSOUR, LYSOUR

$\mathrm{PI}=3.14159265$

1 FORMAT (1H1)

2 FORMAT ( $1 X$, 'STEADY-STATE THERMAL ANALYSIS CALCULATION USING EQS.

1 (13) - (23) OF KOKKAS'/)

FORMAT (1X,' 'THERMAL CONDUCTIVITIES AND LAYER THICKNESSES')

4 FORMAT $\left(1 \mathrm{X},{ }^{\prime} \mathrm{K} 1={ }^{\prime}, \mathrm{F} 10.8,{ }^{\prime} \mathrm{K} 2={ }^{\prime}, \mathrm{F} 10.8,{ }^{\prime} \mathrm{K} 3={ }^{\prime}, \mathrm{F} 10.8\right)$

5 FORMAT (1X, 'L1 = ',F10.5,' L2= ',F10.5,' $\mathrm{L} 3=$ ', F10.5)

6 FORMAT (/1X, 'UPPER SUMMATION LIMITS ',2X,' NUP=', I5,

1 ' MUP $=$ ',I5/)

7 FORMAT $(/ / 1 \mathrm{X}$, 'NUMBER OF HEAT SOURCES=', I5)

8 FORMAT ( $/ 1 X$, 'COORDINATES, LENGTHS, AND WIDTHS OF HEAT SOURCES' $/$ )

9 FORMAT (1X, 'HEAT SOURCE ', 3X, 'WTSOUR', 5X, 'XSOUR', 9X, 'YSOUR', 8X,

1 'LXSOUR', $8 X$, 'LYSOUR' $/$ )

10 FORMAT ( $4 X, I 3,5 X, F 10.5,3 X, F 10.5,3 X, F 10.5,3 X, F 10.5,3 X, F 10.5)$

FORMAT (1X,' 'POWER DENSITY =', F11.6)

12 FORMAT ( $11 X$, 'CALCULATING ', I3,' X POINTS WITH A FIRST POINT OF ' 1 ,F11.6,' AND A STEP SIZE OF ',F11.6)

13 FORMAT( $/ 1 \mathrm{X}$, 'THE CONSTANT $X$ COORDINATE IS ',F11.6)

14 FORMAT (/1X, 'CALCULATING ', I3,' $Y$ POINTS WITH A FIRST POINT OF ' 1 ,F11.6,' AND A STEP SIZE OF ',F11.6)

15 FORMAT (/1X, 'THE CONSTANT Y COORDINATE IS ', F11.6)

16 FORMAT (/1X, 'CALCULATING ', I3,' Z POINTS WITH A FIRST POINT OF ' 1 ,F11.6,' AND A STEP SIZE OF ',F11.6)

17 FORMAT(/IX,'THE CONSTANT Z COORDINATE IS ',F11.6)

27 FORMAT( $1 X$, ' $L X=$ ', F7.2, $3 X$,' $L Y=$ ', $F 7.2$ )

22 FORMAT (1X, F12.4 , 2X, F12.4, 2X, F12.4 , 2X, F12.4)

31 FORMAT $(1 \mathrm{X}, 6 \mathrm{I} 7)$

51 FORMAT $(1 X, I 4,3 X, I 4)$

$52 \operatorname{FORMAT}(1 \mathrm{X}, \mathrm{F} 10.5,3 \mathrm{X}, \mathrm{F} 10.5)$

53 FORMAT $(1 X, I 1)$

54 FORMAT (1X, I4 , 3X, F10.5, 3X, F10.5)

55 FORMAT (1X, F10.5)

56 FORMAT (1X, I2 , 3X, F10.5)

57 FORMAT (1X, F10.5, 3X, F10.5, 3X, F10.5, 3X, F10.5)

88 FORMAT (1X, 'YOUR UPPER LIMIT OF SUMMATION IS TOO LARGE. TRY AGAIN') 


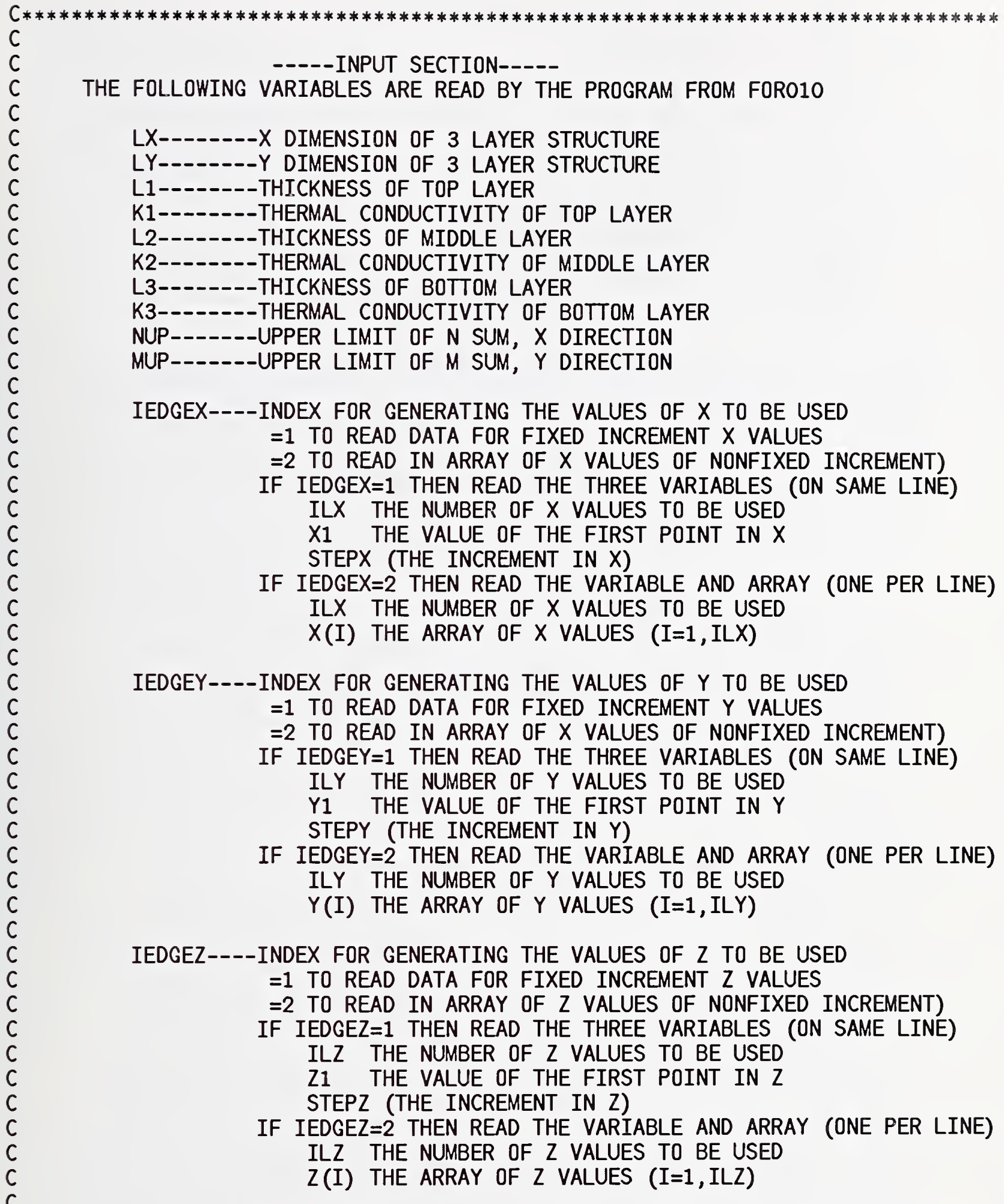

NOTE: ENTER THE Z-RELATED VARIABLES (Z1, STEPZ OR THE Z(I) ARRAY) AS ZERO OR POSITIVE QUANTITIES. THE PROGRAM CONVERTS THE FINAL Z(I) ARRAY TO ZERO OR NEGATIVE QUANTITIES AS THE CALCULATION TAKES THE $Z$ VARIABLE TO BE ZERO OR NEGATIVE. 


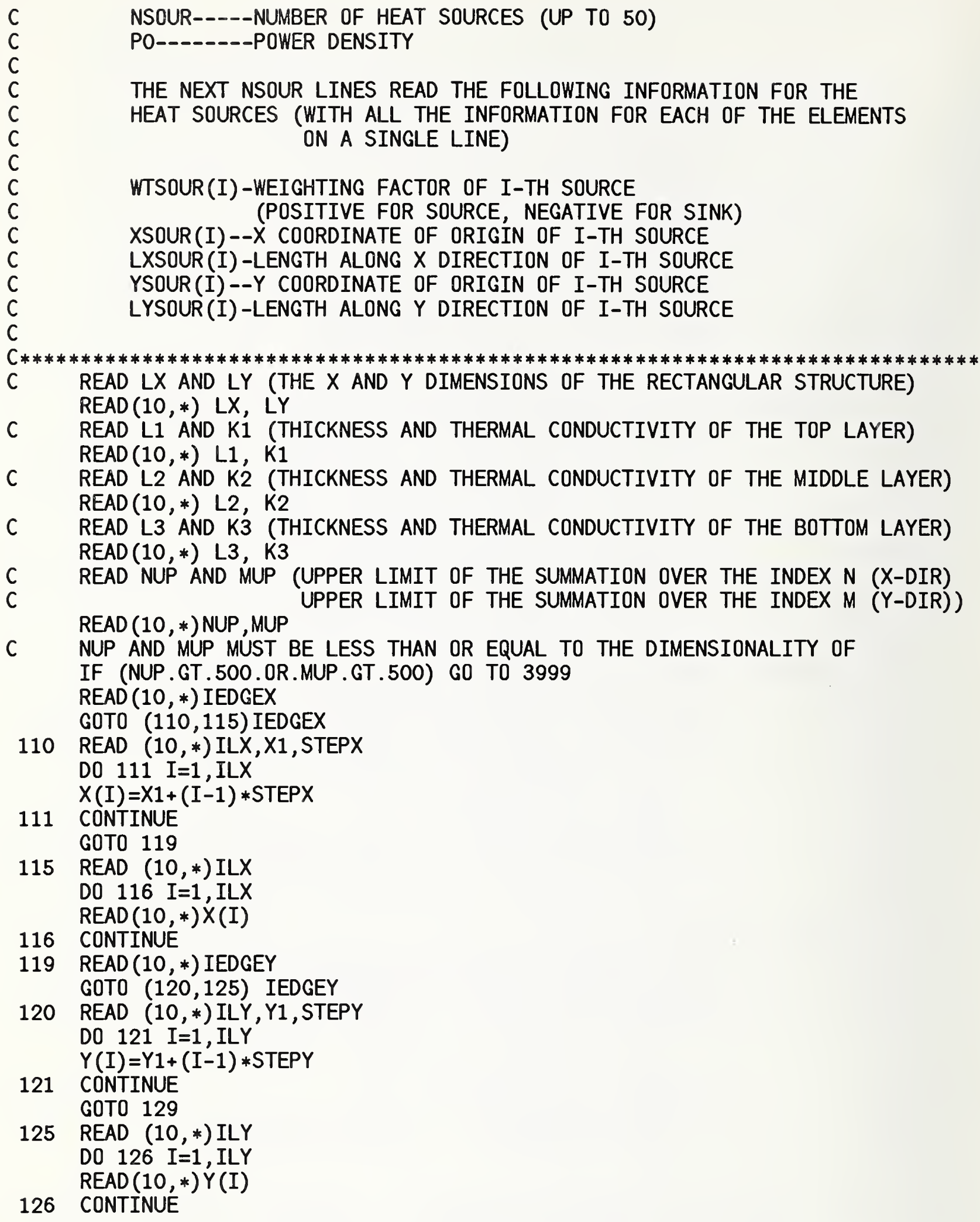


$\operatorname{READ}(10, *)$ IEDGEZ

GOTO $(130,135)$ IEDGEZ

$130 \operatorname{READ}(10, *)$ ILZ , Z1, STEPZ

$\mathrm{Z} 1=-1.0 * \mathrm{Z1}$

STEP $Z=-1.0 *$ STEPZ

DO 131 I=1, ILZ

131 CONTINUE

$Z(I)=Z 1+(I-1) * S T E P Z$

GOTO 139

$135 \operatorname{READ}(10, *) \operatorname{ILZ}$

DO 136 I=1, ILZ

$\operatorname{READ}(10, *) Z(\mathrm{I})$

$Z(I)=-1.0 * Z(I)$

136 CONTINUE

C

READ THE NUMBER OF HEAT SOURCES AND THE POWER DENSITY

C NOTE-POWER DENSITY IS MULTIPLICATIVE FACTOR USUALLY SET EQUAL TO UNITY

$139 \operatorname{READ}(10, *)$ NSOUR , PO PO IS THE POWER DENSITY, ASSUMED UNIFORM FOR ALL HEATERS

C NSOUR IS THE TOTAL NUMBER OF HEATING ELEMENTS ON THE SURFACE OF THE

C THE TOP LAYER (UP TO 50)

c THE NEXT LOOP READS IN THE COORDINATES OF THE ORIGIN OF THE

C HEATING ELEMENTS ALONG WITH THEIR LENGTHS AND WIDTHS

C THE WEIGHTING FACTOR IS ALSO ENTERED (THIS IS REAL, NONINTEGER) DO $100 \mathrm{I}=1$, NSOUR

$\operatorname{READ}(10, *)$ WTSOUR $(I), X S O U R(I), \operatorname{LXSOUR}(I), Y S O U R(I), \operatorname{LYSOUR}(I)$

C WTSOUR(I) IS THE WEIGHTING FACTOR FOR THE I-TH HEATER ELEMENT

C XSOUR(I) IS THE X COORDINATE OF THE ORIGIN OF I-TH HEATER ELEMENT

c LXSOUR(I) IS THE LENGTH OF THE I-TH HEATER ALONG THE $X$ DIRECTION

C YSOUR(I) IS THE Y COORDINATE OF THE ORIGIN OF I-TH HEATER ELEMENT

C LYSOUR(I) IS THE LENGTH OF THE I-TH HEATER ALONG THE Y DIRECTION

100 CONTINUE

PO4LK $=4.0 * P 0 /(L X * L Y * K 1)$

$P I L X=P I / L X$

$P I L Y=P I / L Y$

C******************************************************************************

C

C END OF DATA INPUT SECTION

C BEGIN CALCULATION OF T $(X, Y, Z)$

C THE SUBROUTINES USED IN THE CALCULATION ARE:

C 1) UZERO $(N, M)$ - CALCULATES THE FOURIER COSINE TRANSFORM OF THE

C FUNCTION, $U(X, Y)$, THE POWER DENSITY FUNCTION FOR ALL OF THE

C HEAT SOURCES.

$C$ 2) FUNZ $(N, M, Z)$ - CALCULATES THE Z-DEPENDENT PORTION OF THE SUM

C REMEMBERING THAT THIS IS A FUNCTION OF THE SUMMATION

C INDICES $(N, M)$.

C $* * * * * * * * * * * * * * * * * * * * * * * * * * * * * * * * * * * * * * * * * * * * * * * * * * * * * * * * * * * * * * * * * * * * * * * * * * * * * *$

C CALCULATE THE FOURIER COMPONENTS OF THE HEAT SOURCES, $U(N, M)$

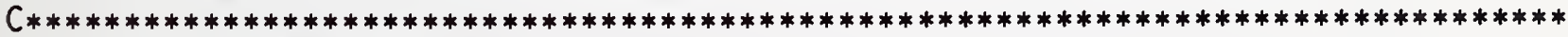

DO 300 MM=1, MUP

$M=M M-1$

DO $250 \quad \mathrm{NN}=1$, NUP

$\mathrm{N}=\mathrm{NN}-1$

$\operatorname{ARUZER}(N N, M M)=\operatorname{UZERO}(N, M)$

250

CONTINUE

300 CONTINUE 


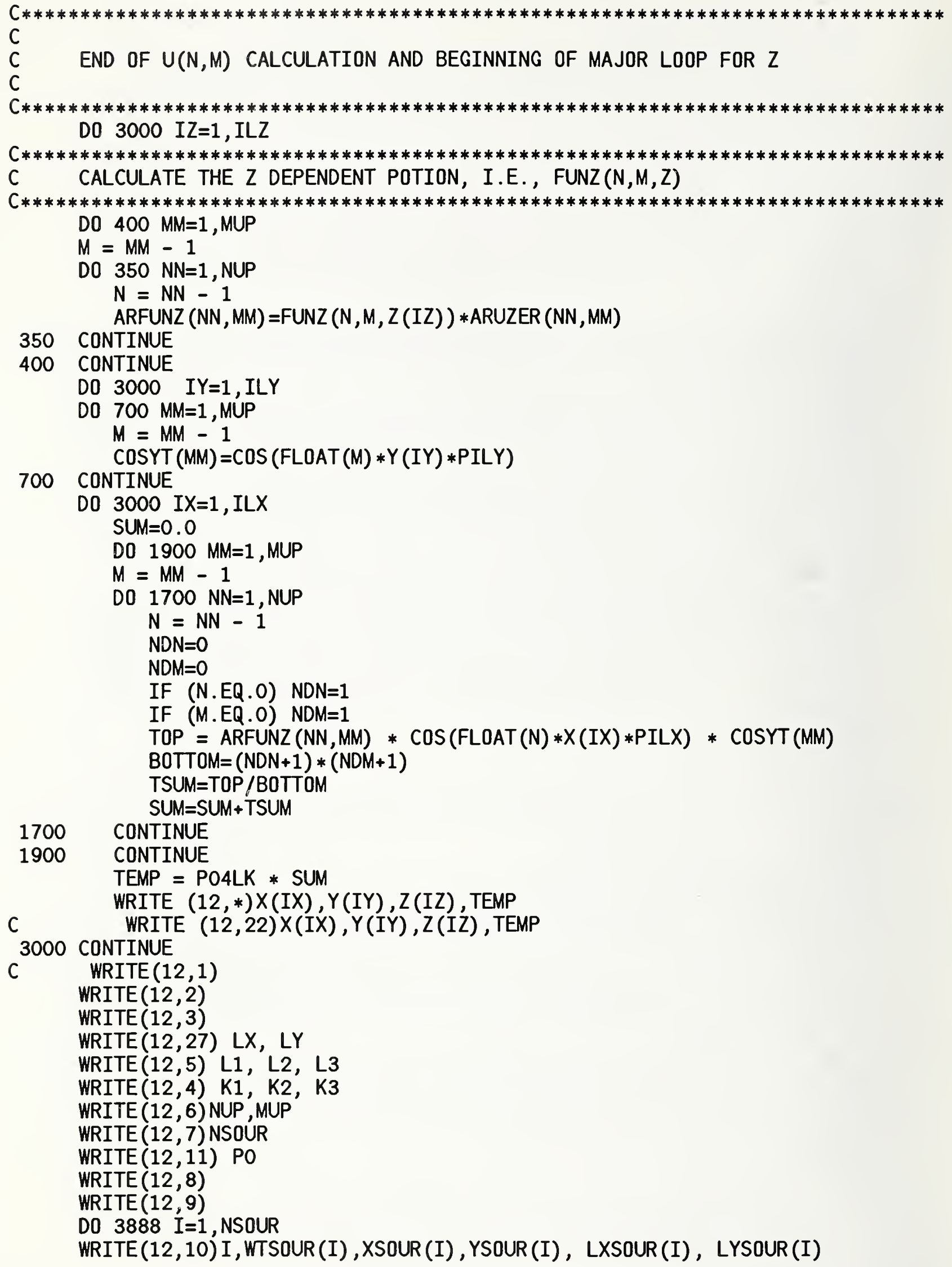




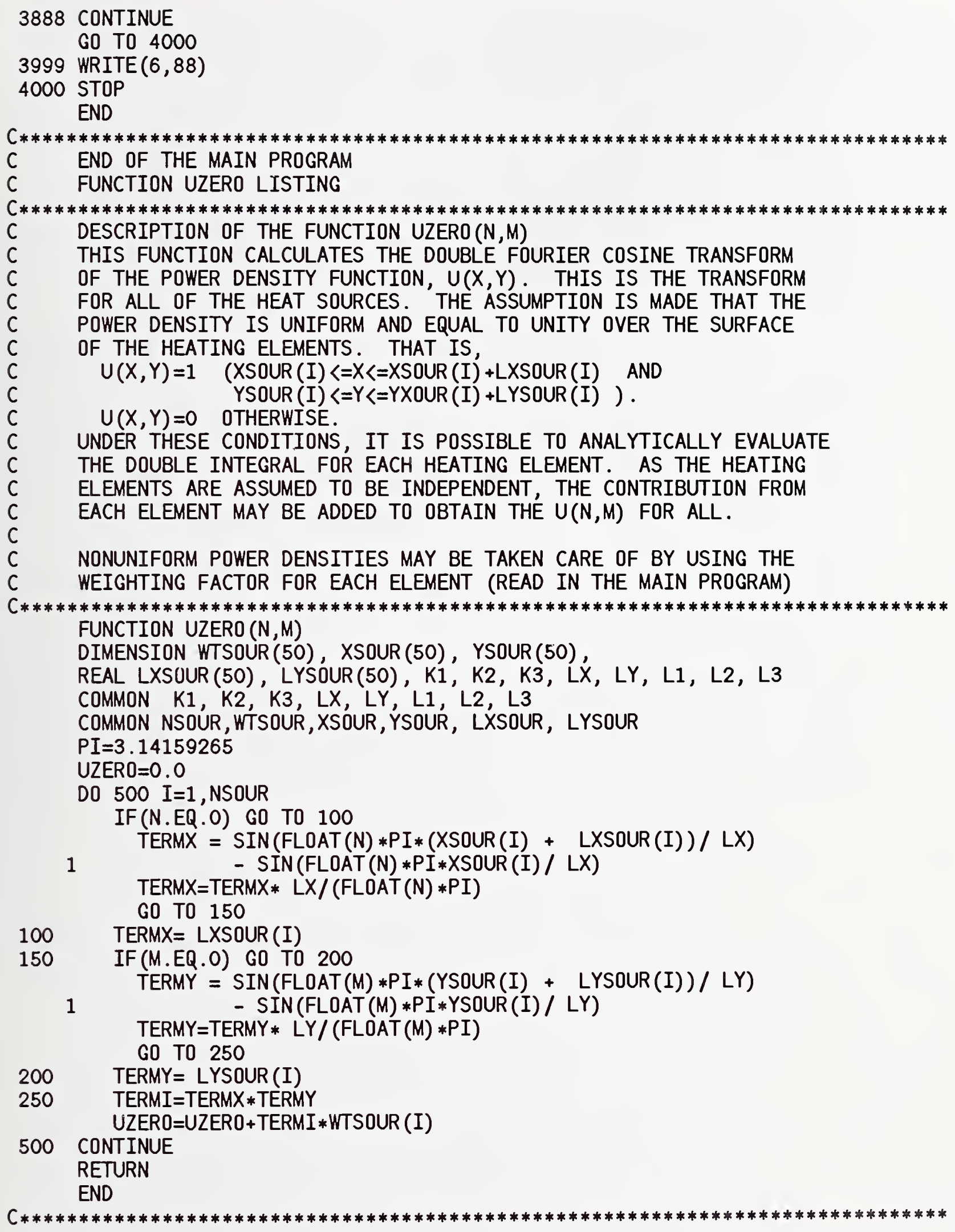


C DESCRIPTION OF THE FUNCTION FUNZ $(N, M, Z)$

C THIS FUNCTION IS USED TO CALCULATE THE $Z$ DEPENDENT PART OF THE

C FUNCTION USING THE S=O VERSIONS OF EQUATIONS (15) - (17) OF KOKKAS.

C THESE ARE USED IN CONJUNCTION WITH EQUATIONS (18)-(22) ALSO FOR

C S $=0$ (STEADY-STATE CONDITION). THE SPECIFIC FORM OF FUNZ IS

C DETERMINED BY THE VALUE OF $Z$, I.E., IF Z FALLS IN THE TOP, MIDDLE

C OR BOTTOM LAYER OF THE STRUCTURE. IN ADDITION, SPECIAL CARE IS

C TAKEN AS TO EVALUATE FUNZ FOR THE CASE WHERE GAMMA $=0$ AS THESE ARE

C SIMPLE, BUT THE COMPUTER DOES NOT KNOW HOW TO EVALUATE LIMITS.

C IN ADDITION, THE FORM OF THE THREE SOLUTIONS HAS BEEN CHANGED TO

C GET RID OF THE ARTIFICIAL OVERFLOW PROBLEMS COMING FROM THE

C HYPERBOLIC FUNCTIONS, COSH AND SINH, FOR THE CASES WHERE THE

C ARGUMENTS BECOME LARGE.

C

FUNCTION FUNZ(N, M, Z)

DIMENSION WTSOUR (50), XSOUR(50), YSOUR(50),

REAL LXSOUR(50), LYSOUR(50), K1, K2, K3, LX, LY, L1, L2, L3

COMMON K1, K2, K3, LX, LY, L1, L2, L3

COMMON NSOUR, WTSOUR, XSOUR, YSOUR, LXSOUR, LYSOUR

$\mathrm{PI}=3.14159265$

GAMMA $=S Q R T((F L O A T(N) * P I / L X) * * 2+(F L O A T(M) * P I / L Y) * * 2)$

$V S=G A M M A * L 1$

$V C=G A M M A * L 2$

$V I=G A M M A * L 3$

$V T=G A M M A *(L 1+Z)$

$V M=G A M M A *(L 1+L 2+Z)$

$V B=G A M M A *(L 1+L 2+L 3+Z)$

BOT1=TANH (VS) $*$ TANH (VI)

$\mathrm{B} 0 \mathrm{~T} 1=\mathrm{B} 0 \mathrm{~T} 1+(\mathrm{K} 3 / \mathrm{K} 2) * \mathrm{TANH}(\mathrm{VS}) * \mathrm{TANH}(\mathrm{VC})$

BOT2 $=(\mathrm{K} 2 / \mathrm{K} 1) * \mathrm{TANH}(\mathrm{VI}) * \mathrm{TANH}(\mathrm{VC})+(\mathrm{K} 3 / \mathrm{K} 1)$

GFUNC $=1.0 /(B O T 1+B O T 2)$

$A Z=A B S(Z)$

IF (AZ.GT. L1) GO TO 500 


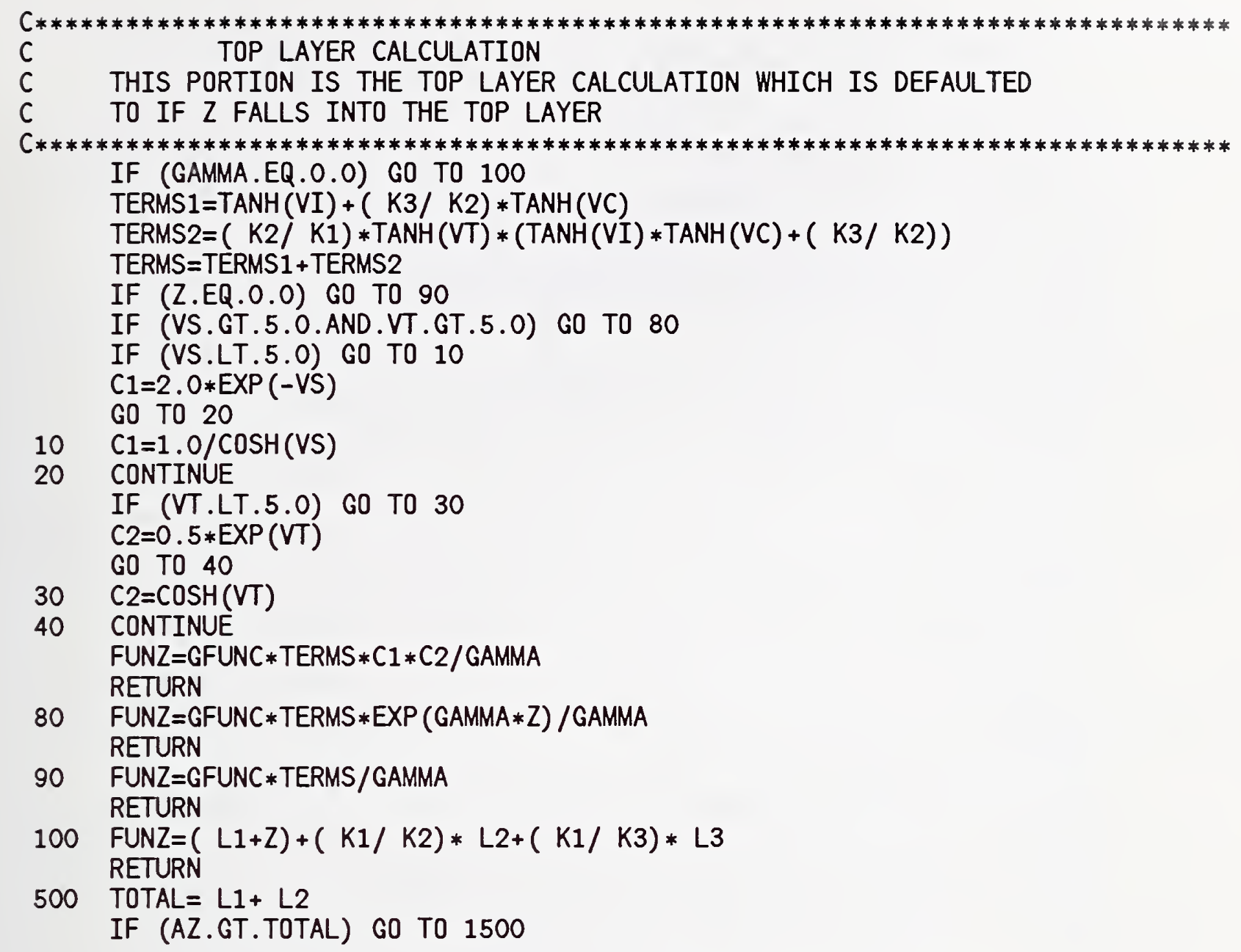




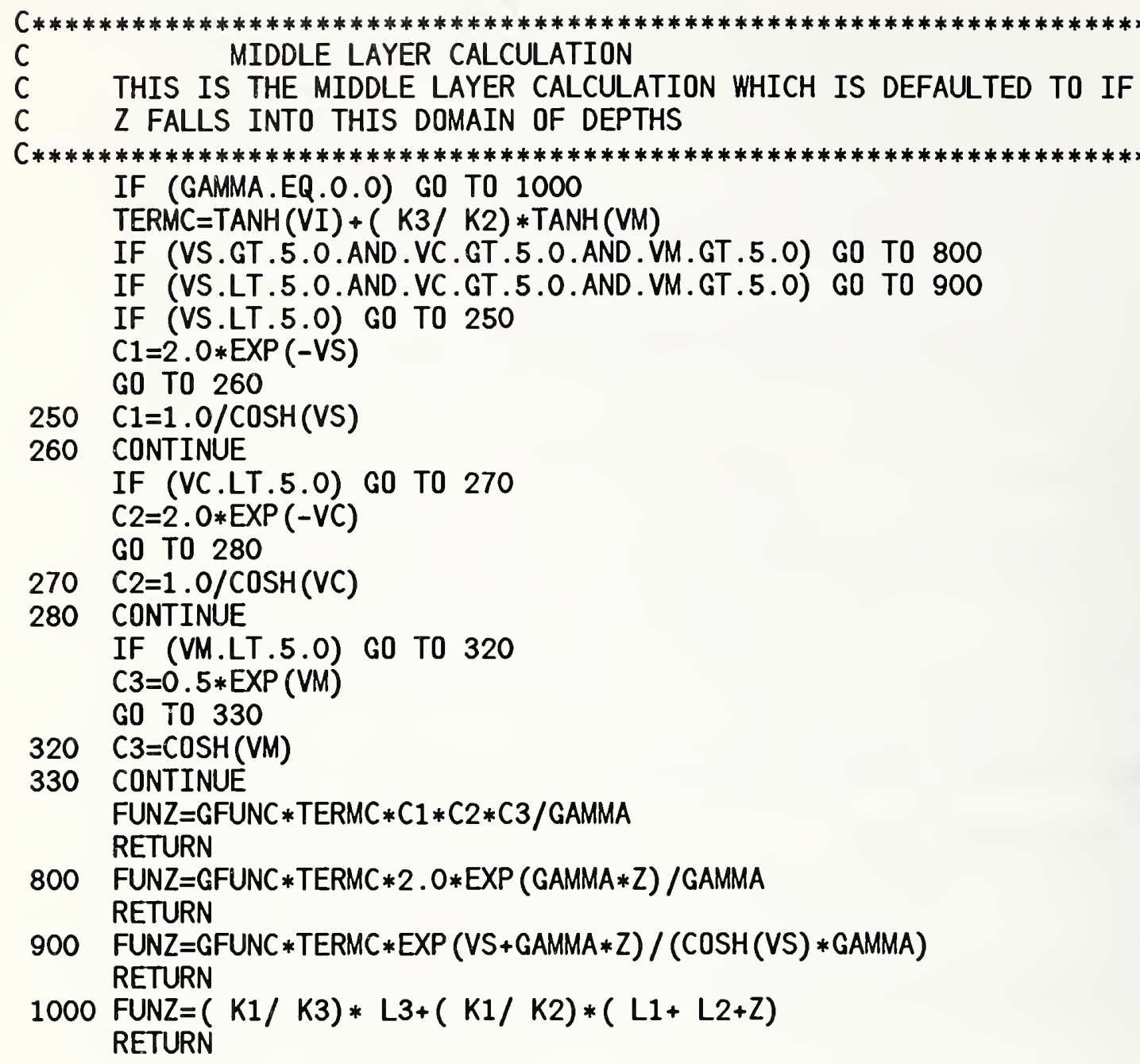




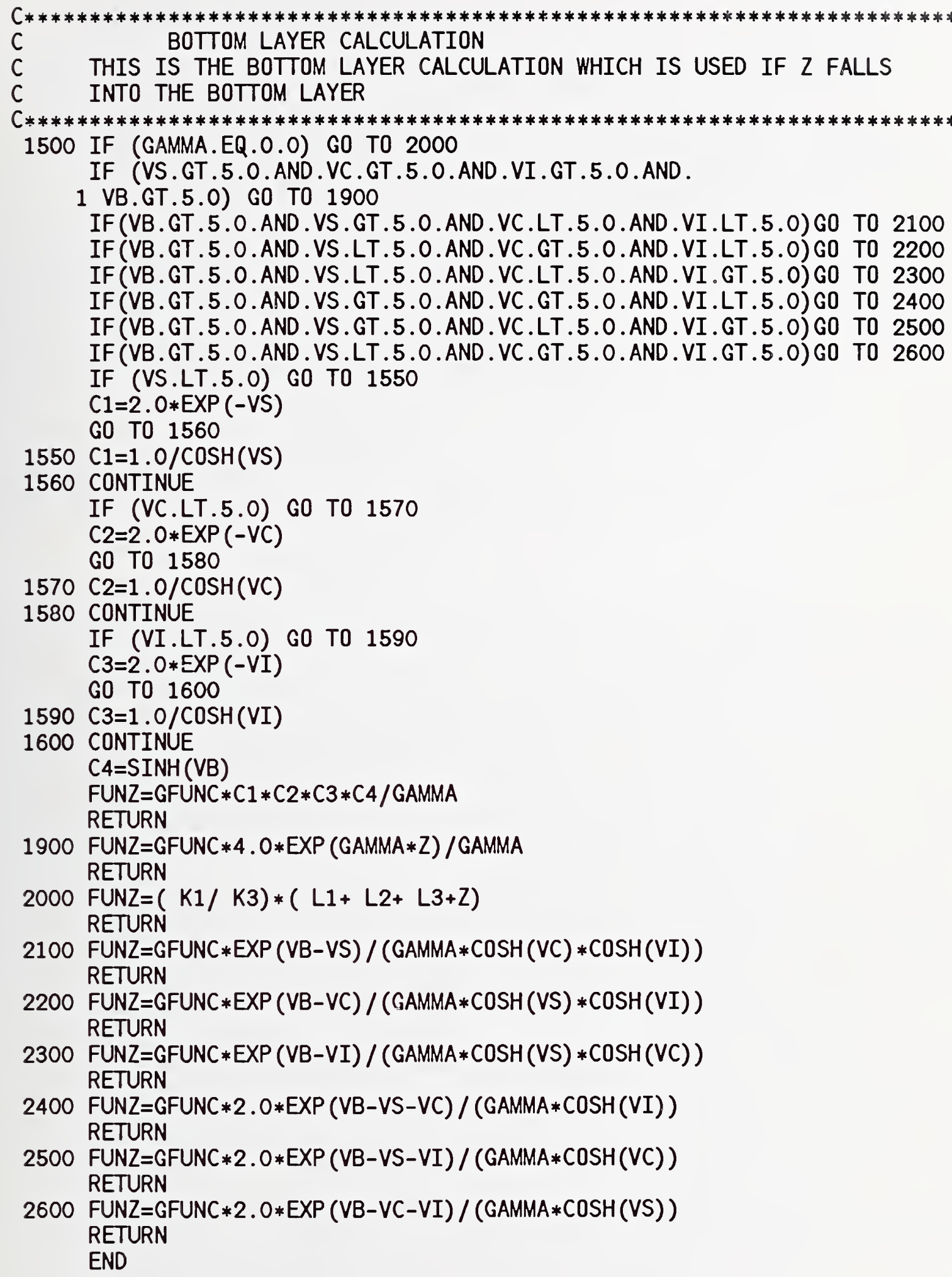





\section{BIBLIOGRAPHIC DATA SHEET}

\begin{tabular}{|l}
\hline 2. PERFORMING ORGANIZATION REPORT NUMBEK \\
\hline $\begin{array}{l}\text { PUBLUCATION DATE } \\
\text { JunE } 1992\end{array}$ \\
\hline
\end{tabular}

4. TITLE AND SUBTITLE

Semiconductor Measurement Technology: Version 2.0 of the TXYZ Thermal Analysis Program: TXYZ20

5. AUTHOR(S)

John Albers

6. PERForming ORganization (IF JOINT OR OTHER THAN NIST, SEE INSTRUCTIONS)

U.S. DEPARTMENT OF COMMERCE

NATIONAL INSTITUTE OF STANDARDS AND TECHNOLOGY (EEEL)

GAITHERSBURG, MD 20899

7. CONTRACT/GRANT NUMBER

8. TYPE OF REPORT AND PERIOD COVERED

Final

9. SPONSORING ORGANIZATION NAME AND COMPLETE ADDRESS (STREET, CITY, STATE, ZIP)

Same as item 6 .

10. SUPPLEMENTARY NOTES

11. ABSTRACT (A 200-WORD OR LESS FACTUAL SUMMARY OF MOST SIGNIFICANT INFORMATION. IF DOCUMENT INCLUDES A SIGNIFICANT BIBUOGRAPHY OR UTERATURE SURVEY, MENTION IT HERE.)

The TXYZ computer program has been used for a number of years for the thermal analysis of semiconductor devices and packages. This program makes use of the closed form, Fourier series solution of the steady-state heat flow equation for the general case of a rectangular three-layer structure with multiple heat sources on the top surface. TXYZ provides for the calculation of the temperature at any set of points in this structure and has proven useful for the determination of the steady-state temperature distribution of semiconductor chips and packages. This report presents TXYZ20 (TXYZ Version 2.0) which is a revised and updated version of the original TXYZ program. The TXYZ20 program incorporates more flexible handling of input data, assignment of positive or negative noninteger weights to the various heat sources or heat sinks, and improved evaluation of limiting forms in the code. The first part of this report consists of a discussion of the general elements in the TXYZ code and the particular changes which have been made to it to obtain TXYZ20. The second part of the report contains a discussion of several examples of the running of the code. Several annotated input data files are presented and discussed to show both the increased flexibility of the input data and the actual use of the updated code. Running the TXYZ20 code for one of the input files provides a benchmark for several machines. The user may wish to run this example for the purpose of comparing the CPU times involved. The appendix contains an annotated, internally documented listing of the FORTRAN source code for TXYZ20. The FORTRAN source code (total of about 21 kbytes) and sample input and output data files are available in ASCII format using a number of transfer vehicles. These include: standard 8 track magnetic tape (ASCII, density $=1600$, record $=80$, block $=1600)$, 5.25-in. $(360$-kbyte and 1.2-Mbyte) DOS-formatted floppy disks, and electronic mail over the Internet. The sample input and output data files are included so that the user can check the program for proper operation as well as to bccomc acquainted with the setup and use of the code. Users of the TXYZ code will find the updated TXYZ20 code easy to use and should benefit from the more flexible input and the more general treatment of heat sources and heat sinks.

12. KEY WORDS (6 TO 12 ENTRIES; ALPHABETICAL ORDER; CAPITALIZE ONLY PROPER NAMES; AND SEPARATE KEY WORDS BY SEMICOLONS)

FORTRAN; Fourier analysis; integrated circuit; semiconductor devices; semiconductor materials; steadystate heat flow; thermal analysis; thermal conductivity

\section{AVAILABIUTY}

UNLIMITED

FOR OFFICIAL DISTRIBUTION. DO NOT RELEASE TO NATIONAL TECHNICAL INFORMATION SERVICE (NTIS).

ORDER FROM SUPERINTENDENT OF DOCUMENTS, U.S. GOVERNMENT PRINTING OFFICE, WASHINGTON, DC 20402.

ORDER FROM NATIONAL TECHNICAL INFORMATION SERVICE (NTIS), SPRINGFIELD, VA 22161.
14. NUMBER OF PRINTED PAGES

33

15. PRICE 



\section{NISTTechnical Publications}

\section{Periodical}

Journal of Research of the National Institute of Standards and Technology-Reports NIST research and development in those disciplines of the physical and engineering sciences in which the Institute is active. These include physics, chemistry, engineering, mathematics, and computer sciences.

Papers cover a broad range of subjects, with major emphasis on measurement methodology and the basic technology underlying standardization. Also included from time to time are survey articles on topics closely related to the Institute's technical and scientific programs. Issued six times a year.

\section{Nonperiodicals}

Monographs-Major contributions to the technical literature on various subjects related to the Institute's scientific and technical activities.

Handbooks-Recommended codes of engineering and industrial practice (including safety codes) developed in cooperation with interested industries, professional organizations, and regulatory bodies.

Special Publications - Include proceedings of conferences sponsored by NIST, NIST annual reports, and other special publications appropriate to this grouping such as wall charts, pocket cards, and bibliographies.

Applied Mathematics Series-Mathematical tables, manuals, and studies of special interest to physicists, engineers, chemists, biologists, mathematicians, computer programmers, and others engaged in scientific and technical work.

National Standard Reference Data Series-Provides quantitative data on the physical and chemical properties of materials, compiled from the world's literature and critically evaluated. Developed under a worldwide program coordinated by NIST under the authority of the National Standard Data Act (Public Law 90-396). NOTE: The Journal of Physical and Chemical Reference Data (JPCRD) is published bimonthly for NIST by the American Chemical Society (ACS) and the American Institute of Physics (AIP). Subscriptions, reprints, and supplements are available from ACS, 1155 Sixteenth St., NW., Washington, DC 20056.

Building Science Series-Disseminates technical information developed at the Institute on building materials, components, systems, and whole structures. The series presents research results, test methods, and performance criteria related to the structural and environmental functions and the durability and safety characteristics of building elements and systems.

Technical Notes-Studies or reports which are complete in themselves but restrictive in their treatment of a subject. Analogous to monographs but not so comprehensive in scope or definitive in treatment of the subject area. Often serve as a vehicle for final reports of work performed at NIST under the sponsorship of other government agencies.

Voluntary Product Standards-Developed under procedures published by the Department of Commerce in Part 10, Title 15, of the Code of Federal Regulations. The standards establish nationally recognized requirements for products, and provide all concerned interests with a basis for common understanding of the characteristics of the products. NIST administers this program as a supplement to the activities of the private sector standardizing organizations.

Consumer Information Series - Practical information, based on NIST research and experience, covering areas of interest to the consumer. Easily understandable language and illustrations provide useful background knowledge for shopping in today's technological marketplace.

Order the above NIST publications from: Superintendent of Documents, Government Printing Office, Washington, DC 20402.

Order the following NIST publications-FIPS and NISTIRs-from the National Technical Information Service, Springfield, VA 22161.

Federal Information Processing Standards Publications (FIPS PUB) - Publications in this series collectively constitute the Federal Information Processing Standards Register. The Register serves as the official source of information in the Federal Government regarding standards issued by NIST pursuant to the Federal Property and Administrative Services Act of 1949 as amended, Public Law 89-306 (79 Stat. 1127), and as implemented by Executive Order 11717 (38 FR 12315, dated May 11, 1973) and Part 6 of Title 15 CFR (Code of Federal Regulations).

NIST Interagency Reports (NISTIR) - A special series of interim or final reports on work performed by NIST for outside sponsors (both government and non-government). In general, initial distribution is handled by the sponsor; public distribution is by the National Technical Information Service, Springfield, VA 22161, in paper copy or microfiche form. 


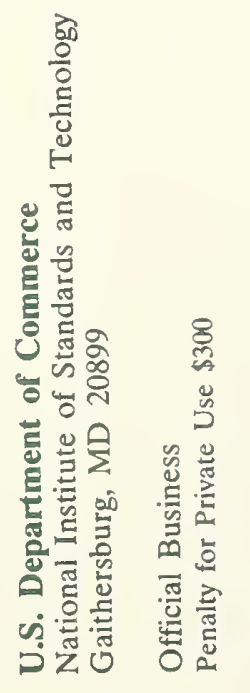

